\title{
The role of bedrock topography, structure, ice dynamics and preglacial weathering in controlling subglacial erosion beneath a high-latitude, maritime ice field
}

\author{
BRice R. REA AND W. BRIAN WhaLLey \\ School of Geosciences, The Queen's University of Belfast, Belfast BT7 1.N.N, Northern Ireland
}

\begin{abstract}
It is known that regions of warm- and cold-based ice sheets modify and protect the landscape, respectively. Investigations on a small plateau-top ice field, Oksfjordjokelen $\left(40 \mathrm{~km}^{2}\right)$, in north Norway have indicated that this situation can exist at a small scale. Margins of the plateau, exposed by ice retreat since AD 1850, provide evidence of a complex basal thermal regime: in some localities blockfields with patterned ground and, in others, abraded and quarried bedrock forelands have been exposed. Exposed blockfields are interpreted as areas covered by cold-based, nonerosive ice. In areas of sliding ice, substantial quantities of erosion are evident. Locally, bedrock shows three joint sets intersecting which produce joint-bounded blocks. Removal of these blocks during the Little Ice Age has produced small rock steps about 5-10 $\mathrm{m}$ long and $1-3 \mathrm{~m}$ high. Present-day basal sliding velocities at the snout are low $\left(15 \mathrm{~m} \mathrm{a}^{1}\right)$ and ice thickness over the whole glacier is $<190 \mathrm{~m}$. Simple modelling for block removal shows a direct relationship with glacier-sliding velocity and inverse relationship with ice thickness. Preglacial weathering is shown to influence the size of removable blocks.
\end{abstract}

\section{INTRODUCTION}

It is known that cold-based and wet-based ice can exist beneath ice sheets and that this thermal differentiation may result in either preservation or modification of the underlying landscape (Sugden and Watts, 1977; Kleman, 1994; Kleman and Borgström, 1994). Such selective erosion/protection is suggested for Oksfjordjokelen, a plateau-top icefield in north Norway.

Oksfjordjokelen is situated approximately $150 \mathrm{~km}$ northeast of Tromso at a latitude of $70^{\circ} 10^{\prime} \mathrm{N}$ (Fig. 1), and covers approximately $40 \mathrm{~km}^{2}$ (Gellatly and others, 1989). Bedrock is composed of mainly Silurian banded gabbros (Krasukopf, 1954) and thus is "mechanically" resistant. Camp Glacier (Fig. 1) is the bext example of the few localities where the glacier margin terminates as a small lobe on top of the plateau (average bedrock slope $<10^{\circ}$ ). A large inner moraine encloses the now deglaciated foreland, with a number of fragmented older moraines outside. The present snout position is approximately $350 \mathrm{~m}$ from the inner (Little Ice Age, LIA) moraine. The foreland covers approximately $0.1 \mathrm{~km}^{2}$ and provides evidence of extensive subglacial quarrying. Beneath the snout a cavity stretches some $70 \mathrm{~m}$ across- and $100 \mathrm{~m}$ up-glacier, providing access beneath ice $\leq 50 \mathrm{~m}$ thick (Rea and Whalley, 1994). The present thermal regime is apparently complex. In some areas the ice is actively sliding, e.g. Camp Glacier (Rea and Whalley, 1994), while in others there is retreat of protective ice. In these localities of protective ice, blockfield covers with patterned ground are being exposed.
At present, four nunataks are located towards the margins, and represent very small sources of supraglacial/ englacial material in the ablation areas no supraglacial material is seen). Thus, everything found in the plateautop moraines can be assumed to have a subglacial origin.

Observations in the cavity at the snout indicate that subglacial water is at atmospheric pressure. The "roughness" of the foreland suggests that during the summer months when sliding velocities are greatest, cavities would have formed. No water-pressure information is available for the localities further up-glacier. For the following analyses, basal water pressures are taken as zero. Such an assumption is probably valid for the snout and localities where basal water pressures are reduced, e.g. during periods of northerly weather in summer when melting is reduced and the subglacial meltwater system is well developed.

This field site provides an excellent opportunity to combine subglacial with proglacial erosion evidence to evaluate how this small outlet has produced substantial amounts of subglacial erosion during the LIA. It should be noted that the erosion is not the removal of blockfield (which covers some areas of the plateau) but the quarrying and plucking of material from coherent bedrock.

\section{SUBGLACIAL EROSION}

Bedrock fracture occurs when the imposed stress exceeds the strength of the bedrock. Plucking is the removal of 


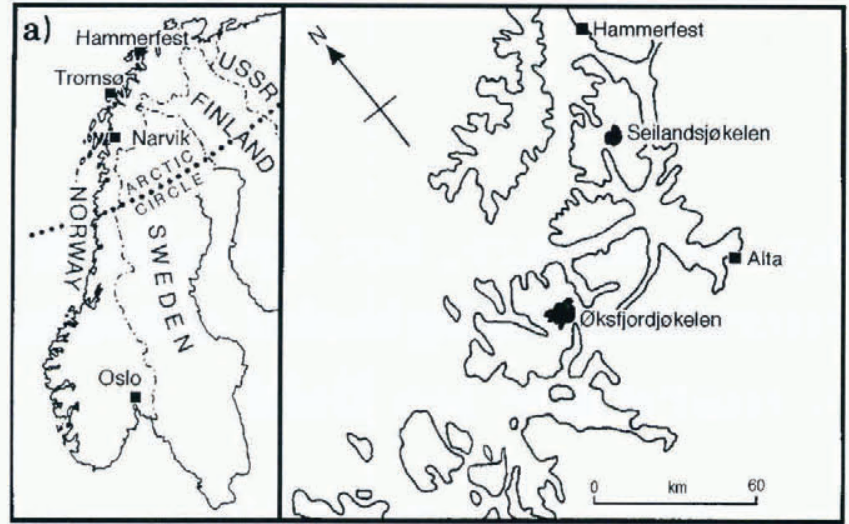

b)

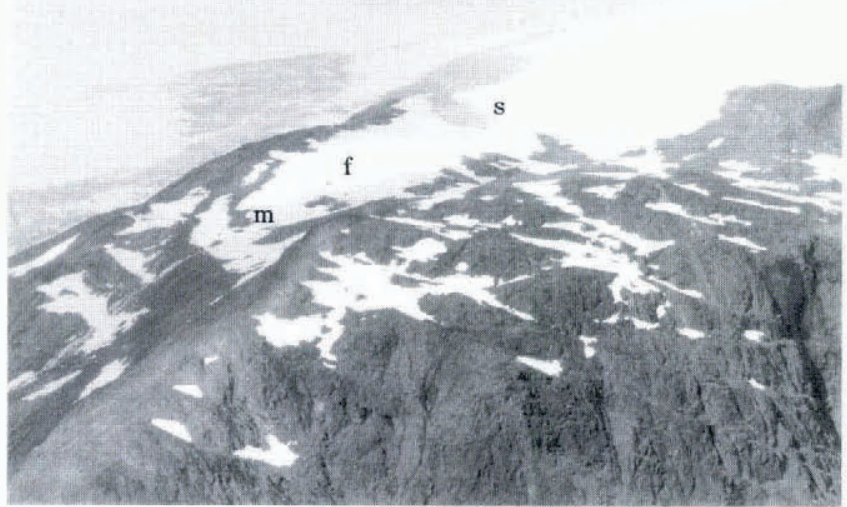

Fig. 1. (a) Location of Oksfjordjokelen. (b) The snout (s) of Camp Glacier is just exposed. The Litlle Ice Age inner moraine $(m)$ is clearly visible but the foreland $(f)$ is still covered by snow.

material produced from fracture processes, or the removal of pre-existing loosened or jointed material. Fracture is most often associated with the lee side of bedrock obstacles where the flow-induced stresses are highest (Morland and Boulton, 1975), shown by the plucked leeside faces of roches moutonnées. The existence of cavities reduces the effective strength of the bedrock, increasing the potential for failure.

Rea (1994a, b) investigated the potential for cavity formation beneath Camp Glacier. The results of these investigations showed that cavities could exist in the lee sides of small ( $<8 \mathrm{~m}$ wavelength) bedrock obstacles (wavelength/amplitude ratio $4: 1$ ). Using the safetyfactor equations from Boulton (1974), Rea (1994a, b) found that there was no likelihood of bed failure from flow-induced stresses alone. However, removal of material is known to have occurred, so other factors such as structure and squeezing of ice must be considered.

\section{Effect of structure}

Although often modelled as an isotropic material, rock has a number of discontinuities through a large range of scales: faults, joints, bedding, foliation, cleavage. At the scales to be dealt with in this paper, joints are the most important. They affect the response of the rock mass especially at pressures below $500 \mathrm{MPa}$ (Morland, 1974), i.e. for pressures generated beneath all known terrestrial ice masses. On the plateau, three major joint sets are identifiable. Two of these are sub-vertical and the third sub-horizontal; the three sets intersect to produce jointbounded blocks which fit together to make up the bed (Rea, 1994a). The shear strength of the jointed bedrock can be taken to lie between one half and one third the value of the intact rock (Jaeger, 1959, 1971). Using the largest possible reduction in strength, Rea (1994a, b) found that, for the reconstructed LIA ice dynamics, no quarrying would have taken place beneath Camp Glacier. The fact that the joints break the bed into blocks is, however, significant. If the blocks can be plucked, subglacial erosion can still proceed without active fracturing of intact bedrock.

\section{Subglacial plucking/shear removal}

Figure 2 shows that the block at the crest of a step can be removed by shear displacement. Once this has been removed, the block behind is exposed to the same shear displacement and removal. This shows how a headward retreat of the lee-side face could occur. From Figure 2 the total resultant shear stress $\left(\tau_{\mathrm{RS}}\right)$ and total normal stress $\left(\sigma_{\mathrm{N}}\right)$ acting on the bottom face of the block is given by:

$$
\begin{aligned}
\tau_{\mathrm{RS}} & =\cos \theta T-\sin \theta\left(\Sigma+B_{\mathrm{w}}\right) \\
\sigma_{n} & =\sin \theta T+\cos \theta\left(\Sigma+B_{\mathrm{w}}\right)
\end{aligned}
$$

where $\Sigma$ is the cryostatic load, $T$ is flow-induced drag, $B_{\mathrm{w}}$ is the weight of the block and $\theta$ is the angle of up-glacier dip of the rock step. Figure 2 is simplified and extra shear resistance from the sides of the block will provide added resistance to that produced along the bottom face.

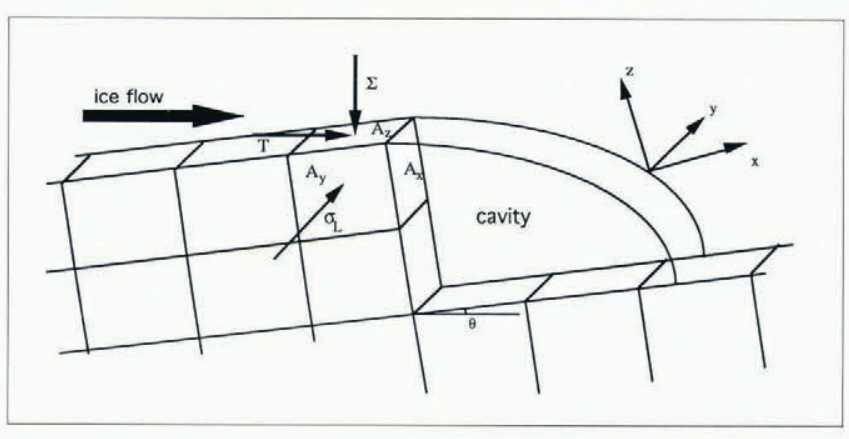

\section{Fig. 2. Cryostatic load, flow of ice over the bed and lateral forces from adjoining blocks provide forces which can be resolved to give shear (removal) and resistive stresses ( $\Sigma=$ cryostatic load, $T=$ flow-induced drag, and $\sigma_{\mathrm{L}}=$ lateral force).}

The Coulomb-Navier law can be used to give the limiting resistance to shear $\left(\tau_{\mathrm{r}}\right)$ along a joint plane (Morland, 1974):

$$
\tau_{\mathrm{r}}=\tau_{\mathrm{jc}}+\mu \sigma_{\mathrm{N}}
$$

where $\mu$ is the coefficient of static friction, and $\tau_{\mathrm{jc}}$ is the joint cohesion. The "cohesive" shear strength of the joint $\left(\tau_{\mathrm{jc}}\right)$ is a function of its roughness such that a joint can still support a shear stress even at zero normal load. Equation (3) describes the situation where joint-bounded blocks 
can be removed from the bed, provided that the glacier can exert a shear stress at the ice/rock interface which exceeds $\tau_{\mathrm{r}}$.

The removal of blocks along the crest of a rock step for horizontal and vertical joint-controlled surfaces has been modelled by Iverson (1989). The conditions modelled were for situations of steady or slowly changing basal water pressures so that water pressures in cracks remained equivalent to cavity water pressures. However, in this analysis basal water pressures are assumed to be atmospheric and the stoss sides of rock steps have a shallow upglacier dip. Following Iverson (1989), Rea (1994b) resolved the forces acting on a block at the crest of a subglacial rock step for an up-glacier dipping stoss surface with basal water pressures taken as atmospheric. The upward frictional support from adjoining blocks must first be calculated in order to determine the total shear resistance. When

$$
\sigma_{\mathrm{N}} A_{z} / 2 A_{y}\left(\tau_{\mathrm{jc}}+\mu \sigma_{\mathrm{L}}\right)>1
$$

where $A$ is the contact area in the $x, y, z$ directions, the block is pressed onto its bottom face and bottom frictional resistance is registered.

Two inequalities allow evaluation of the removal potential of specific block sizes for any ice dynamics, bed configuration and joint characteristics. When the upward frictional support from the sides is exceeded (i.e., Inequality $(4)>1$ ) and frictional force is mobilised along the bottom block face,

$$
\tau_{\mathrm{RS}}>\mu \sigma_{\mathrm{N}}+\left(2 A_{y} / A_{z}\right)\left[\left(\tau_{\mathrm{jc}}+\mu \sigma_{\mathrm{L}}\right)(1-\mu)\right]+\tau_{\mathrm{jc}}
$$

When the upward frictional support from the sides is not exceeded

$$
\tau_{\mathrm{RS}}>2 A_{y} / A_{z}\left(\tau_{\mathrm{jc}}+\mu \sigma_{\mathrm{L}}\right)+\tau_{\mathrm{jc}} .
$$

Using Inequalities (4), (5) and (6) an evaluation of the plucking potential beneath sliding ice is possible.

\section{EVALUATION OF SHEAR REMOVAL BENEATH GAMP GLACIER}

\section{Determination of variables}

Initially, values for $\tau_{\mathrm{jc}}$ and $\mu$ are taken as $3.79 \times 10^{5} \mathrm{~N} \mathrm{~m}^{2}$ and 0.66, respectively (Jaeger and Cook, 1979). Values of $\theta$ will be variable but can be measured in the field subglacially, or on forelands as is the case for this research. A reasonable average from measurements taken on the foreland of Camp Glacier is $13^{\circ}$. The size of the block in question controls the value of $A_{x}, A_{y}, A_{z}$. Over 100 boulders were measured on the inner moraine, and average values for the three major orthogonal axes of a particle $(a, b, c$ axes) were calculated. The average values are $1.38,1.00,0.74 \mathrm{~m}=1.02 \mathrm{~m}^{3}$. For simplicity, this is initially taken as a cubic block with length of side $1 \mathrm{~m}$, which equates to a block of about $3000 \mathrm{~kg}$.

The value of $\Sigma$ is taken simply from the cryostatic load $\left(\rho_{\mathrm{i}} g h\right)$, and $T$ is the drag imparted on the block by ice flow over it. The solution for a cuboid is complex
(Lliboutry, 1979). However, as a first approximation the drag imparted on the block face is inferred from that for a sphere. From Lliboutry $(1979,1987)$ the drag $(T)$ imparted on a hemisphere with cavitation is:

$$
T=\pi R^{2}\left(\sigma_{*}+\Sigma\right) / 2 .
$$

$\sigma_{*}$ is for the condition where velocity from plastic deformation and regelation melting-refreezing are equal, i.e. at the transition wavelength (Nye, 1969) or controlling obstacle size (Weertman, 1957). A cubic block with length of side $1 \mathrm{~m}$ lies within this range.

Horizontal laminar flow is assumed, such that the ice flow is directed perpendicular to the cryostatic load as shown in Figure 2. In Equation (7) the cross-sectional area is given by the term $\pi R^{2} / 2$. This will be replaced by the effective cross-sectional area $\left(E_{\mathrm{csa}}\right)$ of the block which faces vertically up-glacier, i.e. $E_{\mathrm{csa}}=(x \sin \theta)(y)$. Thus Equation (7) can be rewritten

$$
T=E_{\mathrm{csa}}\left(\sigma_{*}+\Sigma\right)
$$

where

$$
\sigma_{*}=\left[5.29 \times 10^{9}\left(v_{\mathrm{i}}\right)^{0.5}\right] / 10
$$

(Lliboutry, 1979).

A reasonable minimum for the lateral stress $\left(\sigma_{\mathrm{L}}\right)$ can be taken as $\Sigma \nu /(1-\nu)$ where $\nu$ is Poisson's ratio $\approx 0.25$ for strong rock; Iverson, 1989), which gives $\sigma_{\mathrm{L}}=1 / 3 \Sigma$ and a reasonable maximum value of $\sigma_{\mathrm{L}}=\Sigma$ (Rea. 1994a).

Rea (1994b) undertook reconstructions for Camp Glacier from its snout position on the inner LIA moraine to the ice divide using an iterative model first used by Schilling and Hollin (1981). An interpolated subglacial bedrock topography was produced from icemarginal bedrock and nunatak heights. Using this bedrock profile the basal ice parameters were finetuned initially to fit the 1976 ice surface. Once a satisfactory fit had been achieved. similar bed conditions were assumed for the LIA and reconstructions completed. The maximum ice thickness was $190 \mathrm{~m}$ and the maximum sliding velocity approximately $15 \mathrm{~m}$ a Rea, 1994b).

\section{Results}

Using the values given above, an evaluation of the upward frictional support on a block from the adjacent blocks is required. From Inequality (4), if $\sigma_{\mathrm{L}}=\Sigma$ the upward frictional support is never $>1$ and friction along the bottom face is not mobilised, but if $\sigma_{\mathrm{L}}=1 / 3 \Sigma$ it is $>1$ beneath ice thickness $>105 \mathrm{~m}$.

Both Inequalities (5) and (6) are required to evaluate the removal potential for blocks. In neither situation is sufficient drag produced by ice movement around the blocks to facilitate shear removal from the bed. These calculations are at best rough approximations, but they do show that there is little chance of the removal of bedrock material beneath Camp Glacier. However, extensive LIA erosion is known to have taken place. Proglacial and subglacial observations showed that many of the joints were iron-stained and had thus been affected by some form of preglacial weathering. 


\section{EFFECT OF WEATHERING}

The value of $\tau_{\mathrm{jc}}$ taken initially of $3.79 \times 10^{5} \mathrm{~N} \mathrm{~m}^{-2}$ from Jaeger and Cook (1979) is for "moderately rough surfaces". There is no information on how weathering will affect this value. It is likely that it will increase the joint-roughness coefficient, i.e., from the preferential action of weathering some minerals will be removed. Normally a higher joint-roughness coefficient would increase the strength of the joint. However, with weathering and removal of crystals, the surface may lose shear strength because exposed crystals on the surface will have little support around them and so are likely to fracture and rotate more easily. Thus, in the absence of any published data, $\tau_{\mathrm{jc}}$ is halved, to $1.895 \times 10^{5} \mathrm{~N} \mathrm{~m}^{2}$, taking account of the weathering. It should be noted that in places on the foreland and in areas of "immature" blockfield, blocks can be removed from in situ positions by hand. In such situations weathering has reduced $\tau_{\mathrm{jc}}$ to zero.

\section{Results}

From Inequality (4) the lateral stresses will be overcome for ice thicknesses $>37 \mathrm{~m}$. Thus, both Inequalities (5) and (6) are required to evaluate the removal potential for blocks. Figure 3 shows that beneath ice of approximately $<50 \mathrm{~m}$ thickness, blocks may be removed from the bed. It is interesting to note that the potential for removal increases as the ice thins the snout represents a region of high potential erosion). This effect is a result of the decrease in normal force on the bottom face of the block, and of the form drag still remaining high. Figure 3 shows that, in certain circumstances, shear removal of blocks is possible. However, there are other bed parameters which can alter the removal potential.

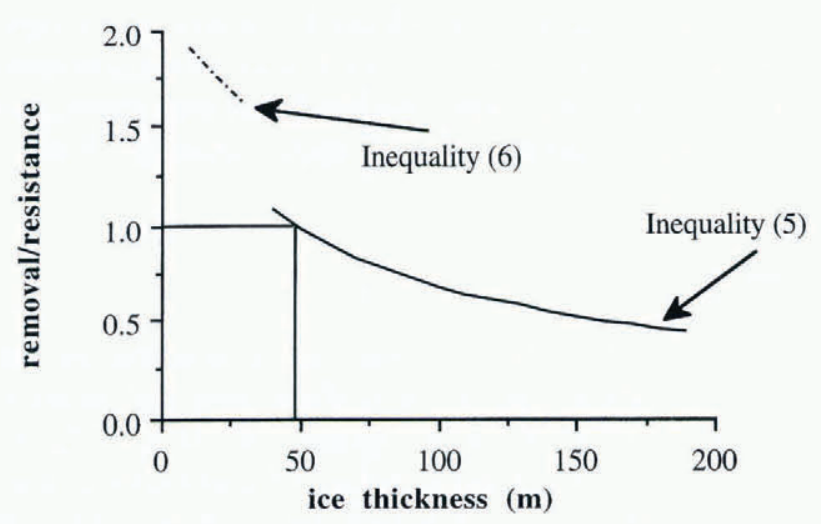

Fig. 3. Blocks can be removed from the bed beneath ice just less than $50 \mathrm{~m}$ thick. (Basal sliding velocity $=15 \mathrm{~m} \mathrm{a}^{\prime}$; $\sigma_{\mathrm{L}}=1 / 3$; weathering has reduced $\tau_{\mathrm{jc}}$ by half.)

\section{BEDROCK PARAMETERS}

Changes in block geometry and up-glacier dip of the stoss side of rock steps will also affect the potential for shear removal of blocks. The following introduces these factors and shows how they may affect the block removal.

\section{Block geometry}

The modelling above was for a $1 \mathrm{~m}^{3}$ rock cube. If blocks are not cubes but cuboid, certain orientations will favour removal while others will reduce removal. On the inner moraine the average $a, b, c$ axes of large blocks were found to be $1.38,1.00,0.74 \mathrm{~m}$. Adopting these values such that the $x, y, z$ axes are now $1.00,1.38,0.74 \mathrm{~m}$, respectively, provides the lowest possible lateral stress and the largest possible shear removal stress. Assuming pre-weathering along joints, then lateral stresses are overcome beneath all thicknesses of ice. Thus Inequality (5) is used to evaluate the shear removal stress. Figure 4a shows that blocks can now be removed beneath ice $<80 \mathrm{~m}$ thick.

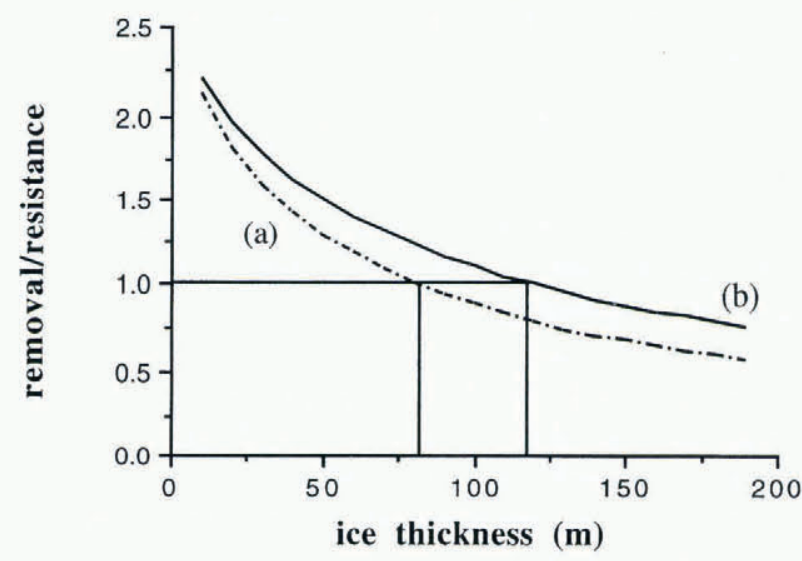

Fig. 4. (a) Modification of the block geometry allows removal beneath ice up to $80 \mathrm{~m}$ thick. (Basal sliding velocity $=15 \mathrm{ma}^{-1} ; \sigma_{\mathrm{L}}=1 / 3$; weathering has reduced $\tau_{\mathrm{jc}}$ by half; $\theta=13^{\circ} ; x, y, z$ axes $=1.00,1.38,0.74 \mathrm{~m}$, respectively.) (b) Using the values above but increasing $\theta$ from $13^{\circ}$ to $20^{\circ}$ enhances the removal potential further.

\section{Dip of stoss faces}

Increasing up-glacier dip $(\theta)$ of the stoss faces allows the lateral stresses to be exceeded under lower ice thicknesses. The greater $\theta$ the lower the normal stress $\sigma_{\mathrm{N}}$, but the form drag increases because $E_{\text {csa }}$ increases. If the bed dip is taken as $20^{\circ}$ and a cuboid block is used, then the potential for block removal is further enhanced (Fig. 4b). It should be noted, however, that the maximum dip up-glacier which could feasibly be considered would be $\approx 30^{\circ}$. Above this, the dip of the down glacier face of the block will gradually decrease, resulting in cavity suppression.

\section{PROGESSES OF REMOVAL ENHANCEMENT}

A number of other processes are known to exist in the subglacial environment which could potentially aid the process of block removal.

Squeezing of glacier ice along lateral joints was first described by Anderson and others (1982). Beneath Camp Glacier the same process has been observed, and indeed it has gone a stage further with ice being squeezed along the bottom face, suggesting that the block is totally encased in ice (Rea, 1994a; Rea and 
Whalley, 1994). The sides provide no frictional resistance to movement, and the presence of ice along the bottom face is likely to reduce $\tau_{\text {jc }}$ effectively to zero. Only the friction along the bottom and sides of the block in contact with ice provide any resistance. In this situation blocks may be easily removed.

Iverson (1991) has shown that, as a result of the reduction in normal stresses for a horizontal rock step, the potential for shear removal of blocks is greater for higher basal water pressures. The hydraulic-jack effect of Röthlisberger and Iken (1981) provides a further mechanism for the removal of joint-controlled blocks from the bed. The reduction of the normal stress on blocks at the cavity origin favours removal (cryostatic load is reduced by the water pressure).

The Robin heat-pump effect (Robin, 1976) relates to the production of cold patches beneath a glacier at the ice/bed interface. From the work of Jellinek (1959), Iverson (1989) gave the shear strength of these adhesion bonds as about $0.2 \mathrm{MPa}$. This could effectively increase $\tau_{\text {RS }}$ by about $25 \%$.

If it occurs, stick-slip motion provides very short periods of rapid movement. High velocities, and thus increased form drag, results in increasing erosion potential.

\section{REGIONS OF PROTECTION}

Beneath parts of Oksfjordjokelen, intact blockfields with sorted stone circles are being exposed by ice retreat. These blockfields are at least pre-LIA in age and probably much older Rea and others, in press; Whalley and others, in press). Thus, past and present ice coverage must have been cold-based. It is likely that only during warm interglacial periods do the outlets slide over their beds and erode. Such problems remain to be fully investigated for this area.

\section{CONGLUSIONS}

Evidence has been presented above to show that this relatively thin, slow-moving plateau-top maritime ice field can produce substantial erosion of a mechanically hard bed. The erosion is controlled by the favourable rock structure such that joints intersect to produce blocks which can be removed from the crest of an up-glacier dipping rock step. Preglacial weathering is also important as it has reduced the "joint cohesion", allowing blocks to be removed more easily. Once entrained these blocks provide ideal abrasion tools. Lliboutry (1994) suggested that little erosion occurs when the preglacially weathered and frost-shattered debris has been removed from the bed. This paper supports his findings to some extent. However, the evidence above also points to the snout being a zone of potentially high erosion, while up-glacier there may be much less occurring, even under faster sliding ice.

\section{ACKNOWLEDGEMENTS}

Thanks go to S. McCarron, J. Hosea and the 1992 Earthwatch Oksfjordjokelen Expedition. B. R. Rea was in receipt of a Department of Education for Northern Ireland Postgraduate Studentship during the field investigations for this paper.

\section{REFERENCES}

Anderson. R. S., B. Hallet, J. Walder and B.F. Aubrey. 1982. Observations in a cavity beneath Grinnell Glacier. Earth Surface Processes and Landforms, 7 1), 63-70.

Boulton, G. S. 1974. Processes and patterns of glacial erosion. In Coates. D. R., ed. Glacial geomorphology. Binghamton, NY. State University of New York, 41-87.

Gellatly, A. F., W. B. Whalley, J. G. Gordon, J. D. Hansom and D. S. Twigg. 1989. Recent glacial history and climate change, Bergsfjord, Troms-Finnmark, Norway. Nor. Geogr. Tidsskr., 431 , 19-30.

Iverson, N. R. 1989. Theoretical and experimental analyses of glacial abrasion and quarrying. Ph.D. thesis, University of Minnesota, Minneapolis.

Iverson. N.R. 1991. Potential effects of subglacial water-pressure fluctuations on quarrying. J. Glaciol., 37 125), 27-36.

Jaeger, J. C. 1959. The frictional properties of joints in rock. Geof. Pure el Appl., 43, 148-198.

Jaeger, J. C. 1971. Elasticity, fracture and flow: with engineering and geological applications. London. Methuen \& Co. Ltd. and Science Paperbacks.

Jaeger, J. C. and N. G. W. Cook. 1979. Fundamentals of rock mechanics. Third edition. London, Chapman and Hall.

Jellinek, H. H. G. 1959. Adhesive properties of ice. J. Colloid Sci., 14 3 , $268-280$.

Krauskopf, K. B. 1954. Igneous and metamorphic rocks of the Oksfjord area, Vest-Finnmark. Vor. Geol. Unders, Arbok 1953, Nr. 188, 2950.

Lliboutry, L. 1979. Local friction laws for glaciers: a critical review and new openings. f. Glaciol., 2389 , 6795.

Lliboutry, L.A. 1987. Very slow flow of solids: basics of modeling in geodynamics and glaciology. Boston, Martinus Nijhoff Publishers.

Lliboutry, L. A. 1994. Monolithologic erosion of hard beds by temperate glaciers. .7. Glaciol., 40 136), $433-450$.

Morland, L. W. 1974. Continuum model of regularly jointed mediums. J. Geoplyss. Res., 79 2), 357-362.

Morland. L. W. and G. S. Boulton. 1975. Stress in an elastic hump: the effects of glacier flow over elastic bedrock. Proc. R. Soc. London, Ser. A, $344(1637), 157-173$.

Nye, J.F. 1969. A calculation on the sliding of ice over a wavy surface using a Newtonian viscous approximation. Proc. R. Soc. London, Ser. I. $311(1506), 445-467$.

Rea, B. R. 1994a. Joint control in the formation of rock steps in the subglacial environment. In Robinson. D. A. and R. B. G. Williams, eds. Rock weathering and landform ezolution. Chichester, John Wiley and Sons, $473-486$.

Rea, B.R. 1994b. Plucking and abrasion beneath temperate plateau icefields. Ph.D. thesis, Queen's University, Belfast.

Rea, B.R. and W.B. Whalley. 1994. Subglacial observations from Oksfjordjokelen, north Norway. Earth Surface Processes and Landforms, $197), 659-673$.

Rea, B. R., W. B. Whalley, M. M. Rainey and J. E. Gordon. In press. Blockfields, old or new? Evidence and implications from some plateaus in northern Norway. Geomorphology.

Robin, G.de Q. 1976. Is the basal ice of a temperate glacier at the pressure melting point? f. Glaciol., 16 74), 183-196.

Röthlisberger, H. and A. Iken. 1981. Plucking as an effect of water-pressure variations at the glacier bed. Ann. Glaciol., 2, 57 62.

Schilling, D. H. and J. T. Hollin. 1981. Numerical reconstructions of valley glaciers and small ice caps. In Denton, G.H. and T.J. Hughes, eds. The last great ice sheets. New York, John Wiley and Sons, 207-220.

Sugden, D. E. and S. H. Watts. 1977. Tors, felsenmeer and glaciation in northern Cumberland Peninsula, Baffin Island. Can. \%. Earth Sci. $1412,2817-2823$.

Weertman, J. 1957. On the sliding of glaciers. F. Glaciol., 321 , 33-38

Whalley. W. B.. B. R. Rea. M. M. Rainey and J. Mc. Alister. In press. Rock weathering in blockfields: some preliminary data from mountain plateaus in north Norway. In Widdowson, M., ed. Palaeosurfaces: recognition, reconstruction and interpretation. London, Geological Society of London. 